\title{
PROX1 Is Associated with Cancer Progression and Prognosis in Gastric Cancer
}

\author{
KOJI UETA ${ }^{1,2}$, YASUNORI OTOWA $^{1,2}$, YOSHIHIRO KAKEJI $^{2}$ and MASANORI HIRASHIMA ${ }^{1}$ \\ ${ }^{1}$ Division of Vascular Biology, Department of Physiology and Cell Biology, and ${ }^{2}$ Division of Gastro-intestinal Surgery, \\ Department of Surgery, Kobe University Graduate School of Medicine, Kobe, Japan
}

\begin{abstract}
Background: It was recently reported that expression of prospero homeobox protein-1 (PROX1) is correlated with the prognosis of esophageal cancer and colorectal cancer. However, its correlation with gastric cancer is unclear. Materials and Methods: Our study analyzed the effect of PROX1 knockdown on the migration, invasion and proliferation of the MKN45 human gastric cancer cell line. The correlation between PROXI expression levels and clinicopathological factors were also analyzed in tumor samples from 99 patients with gastric cancer. Results: Migration, invasion and proliferation were significantly reduced in MKN45 cells with PROX1 knockdown. PROX1 expression was detected in gastric cancer tissues at various levels. PROXI expression levels were positively correlated with cancer stage, $N$ factor, lymphatic vascular invasion, and vascular invasion in patients with gastric cancer. Analysis of overall and recurrence-free survival indicated that high PROXI expression was significantly correlated with poor prognosis. Conclusion: PROXI can be an indicator of poor prognosis and a molecular target for gastric cancer treatment.
\end{abstract}

In recent years, the treatment of cancer has greatly been advanced with the advent of molecular-targeted therapeutic agents. They have an inhibitory effect specifically on cancer cells, but relatively few side-effects compared with conventional anticancer agents. Among them, the progress in chemotherapy for advanced colorectal cancer is remarkable, and the advent of various therapeutic agents, for example, monoclonal antibodies against epidermal growth factor and against vascular endothelial growth factor (VEGF), is

This article is freely accessible online.

Correspondence to: Koji Ueta, Division of Gastro-intestinal Surgery, Department of Surgery, Kobe University Graduate School of Medicine, 7-5-1 Kusunoki-cho, Chuo-ku, Kobe, Hyogo 650-0017, Japan. Tel: +81 783825925, Fax: +81 783825939, e-mail: kokoresult@yahoo.co.jp

Key Words: PROX1, gastric cancer, MKN45, poor prognosis. expected to improve prognosis. On the other hand, in the field of gastric cancer, trastuzumab for human epidermal growth factor receptor 2 (HER2)-positive gastric cancer is the molecular-targeted therapeutic agent that has proven useful, to date. Ramucirumab, which is an antibody against VEGF receptor 2 has become an agent for second-line chemotherapy and is expected to have a therapeutic effect on gastric cancer. However, options for second-line or third-line therapy are fewer than those for colon cancer.

Prospero homeobox protein-1 (PROX1) is a transcription regulator which has been implicated in differentiation of lymphatic endothelial cells (1). Previous studies showed that PROX1 expression levels are correlated with cancer progression and prognosis. For instance, high PROX1 expression in human colon and esophageal cancer tissues is correlated with poor prognosis $(2,3)$. Knockdown of PROX1 by siRNA treatment suppressed proliferation and migration in colon and esophageal cancer cell lines. On the other hand, PROX1 is reported to be a tumor suppressor in neuroblastoma, breast cancer, pancreatic cancer, and hepatocellular carcinoma (4-6). Based on these previous findings, the role of PROX1 in cancer progression or suppression is currently drawing attention, although its mechanism is not fully addressed.

In this study, we examined the correlation of PROX1 expression levels with the migration, invasion, and proliferation of gastric cancer cells and clinicopathological factors of gastric cancer.

\section{Materials and Methods}

Cell lines. Human gastric cancer cell lines, LMSU and MKN45, were purchased from the RIKEN BioResource Center (Tsukuba, Japan) through the National BioResource Project. LMSU and MKN45 cells were cultivated in F-10 and RPMI-1640, respectively, supplemented with $10 \%$ fetal bovine serum (FBS; MP Biomedicals, Santa Ana, CA, USA), 2 mM L-glutamine (Life Technologies, Carlsbad, CA, USA), and penicillin/streptomycin (Life Technologies). Human dermal lymphatic microvascular endothelial cells (HMVEC-dLyNeo; Lonza, Basel, Switzerland) were cultivated in endothelial cell basal medium2 (EBM-2) supplemented with endothelial cell growth medium-2 (EGM-2) SingleQuot Kit (Lonza). 
Transfection in culture. Transfection of cells with scrambled control or PROX1 siRNA (I\#1; HSS108596, \#2; HSS108597, \#3; HSS183490; Invitrogen) was performed using lipofectamine RNAiMAX (Invitrogen), according to the manufacturer's protocol. After $48 \mathrm{~h}$ of transfection, cells treated with siRNA were used for further analysis.

Western blotting. Cells were lysed on ice for $5 \mathrm{~min}$ in $50 \mathrm{mM}$ Tris$\mathrm{HCl}$ (pH7.4) buffer containing 1\% Triton X-100, $150 \mathrm{mM} \mathrm{NaCl}$, $10 \%$ glycerol, $1.5 \mathrm{mM} \mathrm{MgCl}_{2}, 1 \mathrm{mM}$ phenylmethylsulfonyl fluoride, $20 \mathrm{mM} \mathrm{NaF}, 10 \mathrm{mM} \mathrm{Na}_{4} \mathrm{P}_{2} \mathrm{O}_{7}, 2 \mathrm{mM} \mathrm{Na}_{3} \mathrm{VO}_{4}$, protease inhibitor cocktail and phosphatase inhibitor (Merck Millipore, Darmstadt, Germany). The cell lysate was recovered by using a cell scraper and clarified by centrifugation at $4^{\circ} \mathrm{C}$ for $10 \mathrm{~min}$. Equal amounts of protein in the supernatant ware loaded for sodium dodecyl sulfate-polyacrylamide gel electrophoresis and transferred to polyvinylidene fluoride membranes (Merck Millipore). Rabbit anti-PROX1 (1:2,500; BioLegend) and mouse anti- $\beta$-actin $(1: 10,000 ;$ Sigma) antibodies were used as primary antibodies, and anti-rabbit $\operatorname{IgG}$ and anti-mouse $\operatorname{IgG}$ antibodies conjugated to horseradish peroxidase were used as secondary antibodies. Enhanced chemiluminescence (PerkinElmer, Waltham, MA,USA) was used for detection with LAS-2000 (Fujifilm, Tokyo, Japan). To quantify phosphorylated protein per total protein, the densitometric analysis of digital images was performed using ImageJ software (National Institutes of Health, Bethesda, MD, USA).

Fluorescent immunocytochemistry. MKN45 cells treated with control or PROX1 siRNA were cultivated on a cover glass for 24 $\mathrm{h}$, fixed with $1 \%$ paraformaldehyde in phosphate-buffered saline (PBS) at $4^{\circ} \mathrm{C}$ for $20 \mathrm{~min}$, washed three times with PBS at room temperature (RT) for $2 \mathrm{~min}$, incubated with PBS containing $0.2 \%$ Triton X-100 at RT for $10 \mathrm{~min}$, and washed three times with PBS at RT for $2 \mathrm{~min}$. Cells were then blocked in $1 \%$ bovine serum albumin in PBS at RT for $1 \mathrm{~h}$ and incubated with rabbit anti-PROX1 antibody $(1: 1,000)$ in blocking solution at $4^{\circ} \mathrm{C}$ overnight. Cells were washed three times with PBS at RT for $2 \mathrm{~min}$, followed by incubation with PBS containing 4',6-diamidino-2-phenylindole (Invitrogen) and anti-rabbit IgG antibody conjugated to cyanine dye 3 (Jackson ImmunoResearch). Cells were washed three times with PBS at RT for 2 min, mounted on cover glass with mowiol (7), and analyzed by inverted microscopy (IX81; Olympus, Tokyo, Japan).

Migration assay. MKN45 cells treated with control or PROX1 siRNA were cultivated to be confluent monolayers in 12-well plates. Confluent monolayers of cells were scratch-wounded by pipette tip and were washed with PBS twice, and cultivated for $48 \mathrm{~h}$. The width of the wound was measured at 0 and $48 \mathrm{~h}$.

Invasion assay. Cell invasion was assessed by trans-well migration assay using the Cytoselect assay kit (Cell Biolabs, San Diego, CA, USA), according to the manufacturer's protocol. Three-hundred microliters of serum-free Dulbecco's modified Eagle's medium containing $3.0 \times 10^{5} \mathrm{MKN} 45$ cells treated with control or PROX1 siRNA were placed in a $8 \mu \mathrm{m}$ pore polycarbonate membrane cell culture insert precoated with basement membrane matrix. The outer chamber was filled with RPMI-1640 containing $10 \%$ FBS as the chemoattractant for cells to migrate through pores. After incubation for $72 \mathrm{~h}$, cells of the membrane were fixed with $3.7 \%$ formaldehyde in PBS. Cells on the upper surface of the membrane were mechanically removed by cotton swab. Migrating cells on the lower surface were stained and counted in three random fields for each membrane, followed by measurement of absorbance at OD $560 \mathrm{~nm}$ for quantification of invasive cells.

Proliferation assay. Fourteen thousand MKN45 cells treated with control or PROX1 siRNA were cultivated for $48 \mathrm{~h}$ and the number of cells was determined using ATPLite assay kit (PerkinElmer), according to the manufacturer's protocol.

Clinical samples. Surgical samples used in this study were obtained from 99 consecutive patients with gastric cancer who underwent surgery between January 2011 and December 2012 at the Division of Gastrointestinal Surgery, Department of Surgery, Kobe University Hospital (Kobe, Japan). None of the patients received preoperative chemotherapy or radiotherapy. All resected samples were fixed in $3.7 \%$ formaldehyde in PBS and embedded in paraffin. Pathological stage of gastric cancer was determined based on the seventh edition of the TNM classification of the Union for International Cancer Control (UICC) (8). Clinicopathological parameters at the time of the surgery were retrieved from medical records. Survival was measured from the time of surgery until follow-up on June 31, 2017.

Immunohistochemistry. Paraffin-embedded tumor tissues of patients with gastric cancer were cut into $4-\mu \mathrm{m}$ thick sections. After removing paraffin, sections were washed with PBS, and heat-treated for $20 \mathrm{~min}$. Immunostaining with rabbit anti-PROX1 antibody was performed using an autostainer Bond Max (Leica Microsystems), according to the preinstalled protocol. PROX1 expression levels in gastric cancer were scored as previously (3), based on the percentage of positively stained cells; 0 , not detected in nuclei; 1 , 0-20\% staining; 2, 21-50\% staining; and 3, 51-100\% staining. Samples with score $0 / 1$ and $2 / 3$ were classified as low expression and high expression groups, respectively.

Statistical analysis. Values are presented as the mean \pm standard error of the mean. At least three specimens were analyzed in all cases. The unpaired two-tailed Student's $t$-test was performed to compare the results between two groups. One-way analysis of variance was used for inter-group comparisons, and Tukey-Kramer method was used for group comparisons. Chi-square test was performed to compare the actual survival to expected numbers. Overall and recurrence-free survival were measured from the day of surgery and plotted according to the Kaplan-Meier method; the log-rank test was used for comparison. Cox proportional hazards regression was used to test independent prognostic contribution of PROX1. All statistical analyses were performed using EZR software (9). $p$ Values of less than 0.05 were accepted as being significant.

\section{Results}

PROX1 plays a role in migration, invasion and proliferation of gastric cancer cells. To investigate the effect of PROX1 expression on the oncogenic cellular behavior of gastric cancer cells, we first investigated PROX1 expression in LMSU and MKN45 cell lines by western blotting. Whereas expression of PROX1 was not detected in LMSU cells, it was highly expressed in MKN45 cells (Figure 1A). We, therefore, decided to use MKN45 cells for further analysis. 

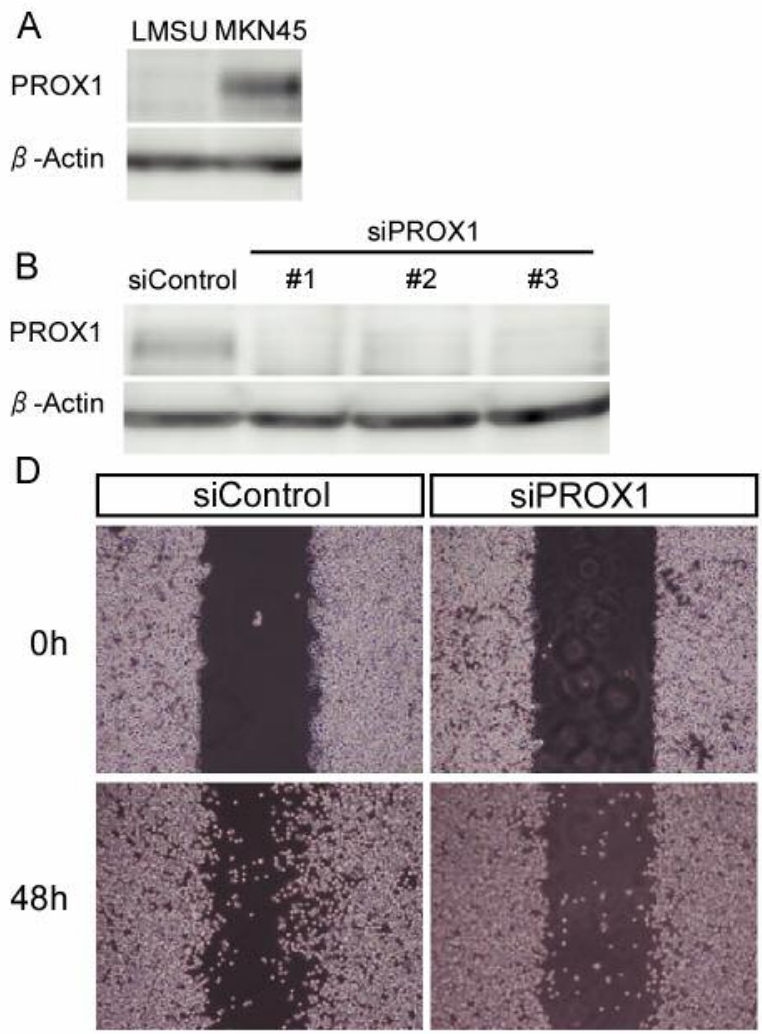

C
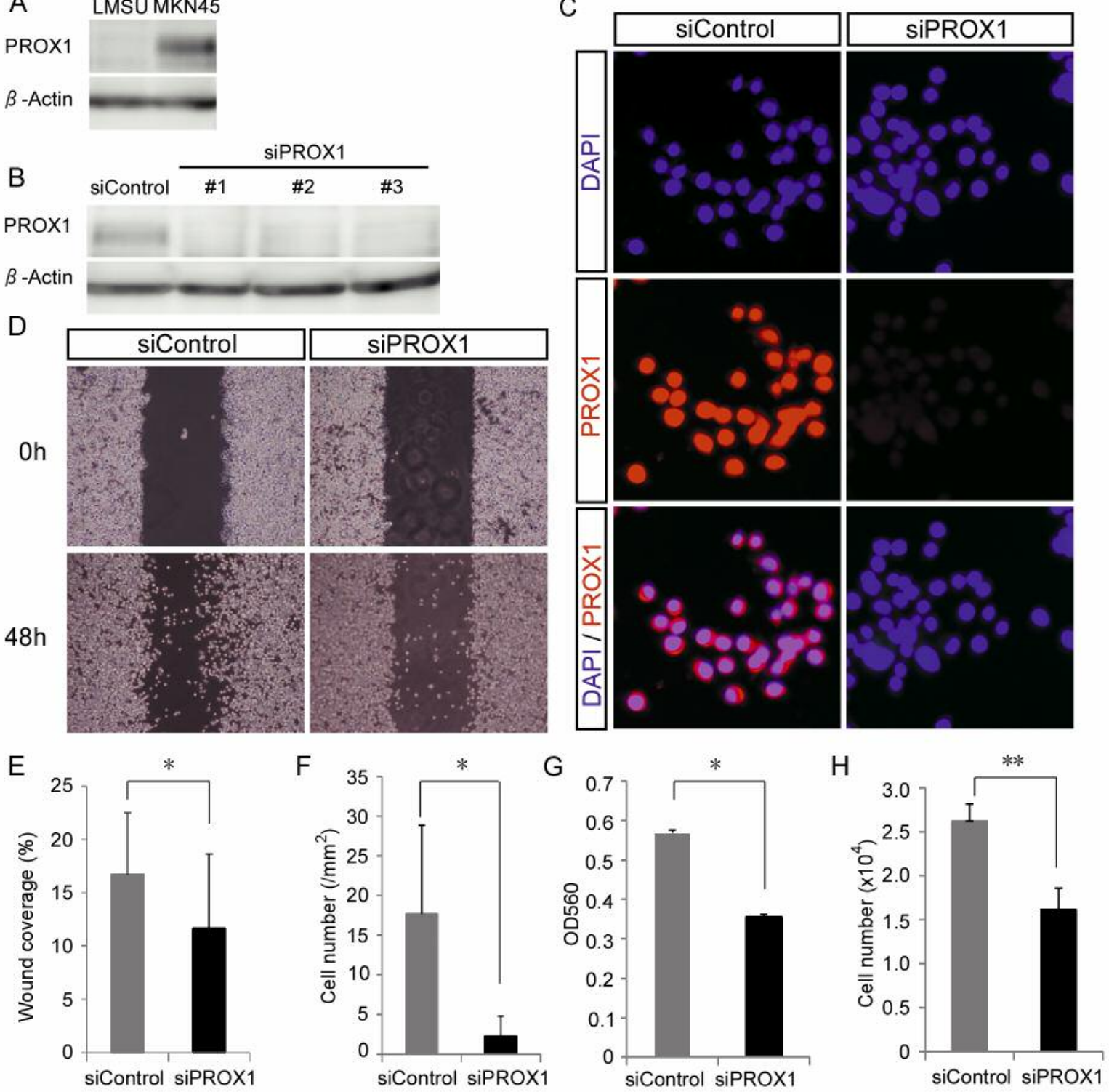

Figure 1. Prospero homeobox protein-1 (PROX1) knockdown inhibits migration, invasion and proliferation of MKN45 gastric cancer cells. A: Western blot for PROX1 expression in LMSU and MKN45 gastric cancer cell lines. B: Western blot for PROX1 expression in MKN45 gastric cancer cells treated with scrambled control siRNA (siControl) or PROX1-specific siRNAs (siPROX1 \#1-3). C: Immunostaining analysis of PROX1 expression in MKN45 gastric cancer cells treated with siControl or siPROX1 (\#1). D,E: Migration assay of MKN45 cells treated with siControl or siPROX1 (n=3 each). F, G: Invasion assay of MKN45 cells treated with siControl or siPROX1. The number of invading cells $(F)$, and absorbance OD 560 $n m$ which represents invading cell number $(G)$ are shown $(n=5$ each). $H$ : The number of MKN45 cells after treatment with siControl or siPROX1 was evaluated by luminescence ATP detection assay $(n=5$ each). Significantly different at $* p<0.05$ and $* * p<0.01$ as determined by unpaired twotailed Student's t-test.

To check whether PROX1 expression can be suppressed, MKN45 cells were transfected with scrambled control siRNA or three different PROXI-specific siRNAs (siRNA \#1-3). Western blotting and fluorescent immunostaining confirmed that all three PROXI siRNAs greatly reduced PROX1 protein levels at $48 \mathrm{~h}$ after transfection, compared with scrambled control siRNA (Figure 1B and C). Thus, we used PROXI siRNA \#1 for further analysis of PROXI knockdown experiments.

We examined whether PROX1 plays a role in migration of gastric cancer cells by wound-healing assay. At $48 \mathrm{~h}$ after wounding, the wound closure was significantly delayed by 

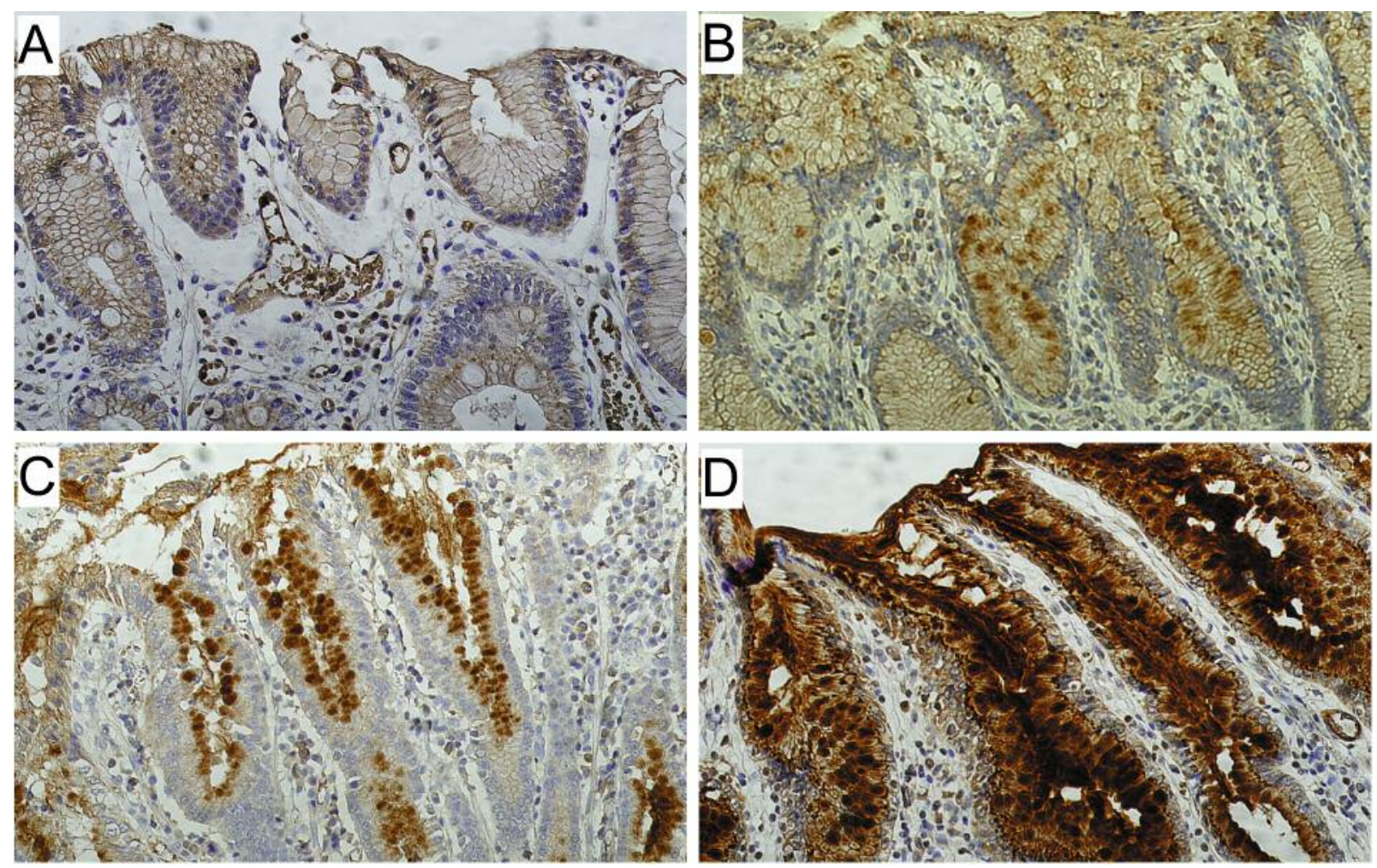

Figure 2. Prospero homeobox protein-1 (PROX1) expression detected in gastric cancer tissues at various levels. Representative images of immunostained tumor tissues are shown and were scored based on the percentage of positively stained cells: A: $0:$ Staining not detected in nuclei; B: 1: 0-20\% staining; $C: 2: 21-50 \%$ staining; and D: 3: 51-100\% staining. All images were taken at $\times 20$ magnification.

PROX1 knockdown, compared to control knockdown (Figure 1D). We next evaluated cell invasion by trans-well migration assay. Cell invasion was significantly suppressed by PROXI knockdown, compared to control knockdown (Figure $1 \mathrm{~F}$ and $\mathrm{G})$. Cell proliferation was then evaluated by luminescence ATP detection assay. The number of cells was significantly reduced by PROX1 knockdown, compared to control knockdown (Figure 1H). These results indicate that PROXI expression levels are positively correlated with migration, invasion, and proliferation of gastric cancer cells.

Various levels of PROX1 expression are detected in gastric cancer tissues. To study the prognostic role of PROX1 expression levels in human gastric cancer, we investigated PROX1 expression in human gastric cancer tissues obtained from 99 patients by immunohistochemical analysis with antiPROX1 antibody. PROX1 was barely detected in normal gastric mucosa. According to the degree of PROX1 nuclear staining, gastric cancer tissues were classified into two categories: low expression when $20 \%$ or fewer cells were stained, high expression when $>20 \%$ of cells were stained (Figure 2). PROX1 expression was scored low in $58(0 \%$, $\mathrm{n}=15 ; 1-20 \%, \mathrm{n}=43)$ and high in $41(21-50 \%, \mathrm{n}=27 ; 51-$ $100 \%, \mathrm{n}=14$ ) samples with gastric cancer.

PROX1 expression levels are correlated with clinicopathological factors of gastric cancer. patients and prognostic significance. Patient and tumor characteristics are summarized in Table I. The median (interquartile range) age for patients of the low-expression group was 70 (40-84) years, whereas that for the high-expression group was 69 (44-82) years. Higher PROX1 expression was significantly correlated with poor prognosis by cancer stage, $\mathrm{N}$ factor, lymphatic vascular invasion, and vascular invasion. However, no significant differences were observed in age, gender, tumor location and histology, $\mathrm{T}$ factor, $\mathrm{M}$ factor, or preoperative serum tumor marker examination.

We analyzed the correlation between PROX1 expression level and survival rate of patients with gastric cancer (Figure 3). Five-year overall survival of patients with gastric cancer with high PROX1 expression was significantly lower than that of those with low PROX1 expression (55.7\% vs. 89.8\%, $p<0.001)$. Recurrence-free survival of patients with high PROX1 expression was similarly lower than that of those with low 
Table I. Prospero homeobox protein-1 (PROX1) expression level according to clinicopathological factors of patients with gastric cancer and prognostic significance.

\begin{tabular}{|c|c|c|c|}
\hline \multirow[t]{2}{*}{ Factor } & \multicolumn{2}{|c|}{ PROX1 expression } & \multirow[t]{2}{*}{$p$-Value } \\
\hline & Low $(\mathrm{n}=58)$ & High $(n=41)$ & \\
\hline \multicolumn{4}{|l|}{ Age } \\
\hline$<65$ Years & 17 & 11 & \multirow[t]{2}{*}{0.79} \\
\hline$\geq 65$ Years & 41 & 30 & \\
\hline \multicolumn{4}{|l|}{ Gender } \\
\hline Male & 41 & 34 & \multirow[t]{2}{*}{0.16} \\
\hline Female & 17 & 7 & \\
\hline \multicolumn{4}{|l|}{ Location } \\
\hline Upper & 21 & 12 & \multirow[t]{3}{*}{0.25} \\
\hline Middle & 28 & 17 & \\
\hline Lower & 9 & 12 & \\
\hline \multicolumn{4}{|l|}{ Histology } \\
\hline Well/mod & 26 & 21 & \multirow[t]{2}{*}{0.54} \\
\hline Poor/sig & 32 & 20 & \\
\hline \multicolumn{4}{|l|}{ pT } \\
\hline $\mathrm{T} 1-2$ & 44 & 27 & \multirow[t]{2}{*}{0.28} \\
\hline T3-4 & 14 & 14 & \\
\hline \multicolumn{4}{|l|}{$\mathrm{pN}$} \\
\hline No & 46 & 17 & \multirow[t]{2}{*}{0.0002} \\
\hline $\mathrm{N} 1-3$ & 12 & 24 & \\
\hline \multicolumn{4}{|l|}{$\mathrm{pM}$} \\
\hline M0 & 58 & 39 & \multirow[t]{2}{*}{0.10} \\
\hline M1 & 0 & 2 & \\
\hline \multicolumn{4}{|l|}{ pStage } \\
\hline I-II & 49 & 26 & \multirow[t]{2}{*}{0.02} \\
\hline III-IV & 9 & 15 & \\
\hline \multicolumn{4}{|l|}{ ly } \\
\hline Negative & 38 & 18 & \multirow[t]{2}{*}{$\mathbf{0 . 0 3}$} \\
\hline Positive & 20 & 23 & \\
\hline \multicolumn{4}{|l|}{$\mathrm{v}$} \\
\hline Negative & 37 & 15 & \multirow[t]{2}{*}{0.007} \\
\hline Positive & 21 & 26 & \\
\hline
\end{tabular}

ly, Lymphatic vascular invasion; mod, moderately differentiated; $p$, pathological; poor, poorly differentiated adenocarcinoma; sig, signetring cell carcinoma; vascular invasion; well, well-differentiated Unpaired two-tailed Student's $t$-test: significant values shown in bold.

PROX1 expression $(52.1 \%$ vs. $88.1 \%, p<0.001)$. Multivariate analysis of the association between clinicopathological parameters and prognosis of gastric cancer showed PROX1 expression to be the second main factor associated with risk of death, with a hazard ratio (95\% confidence interval) of 3.647 (1.294-10.28), after tumor stage with a hazard ratio (95\% confidence interval) of 6.479 (2.476-16.95).

\section{Discussion}

In this study, we showed that migration, invasion, and proliferation of gastric cancer cells were positively enhanced by PROX1 expression. In clinical analysis, we identified that
A

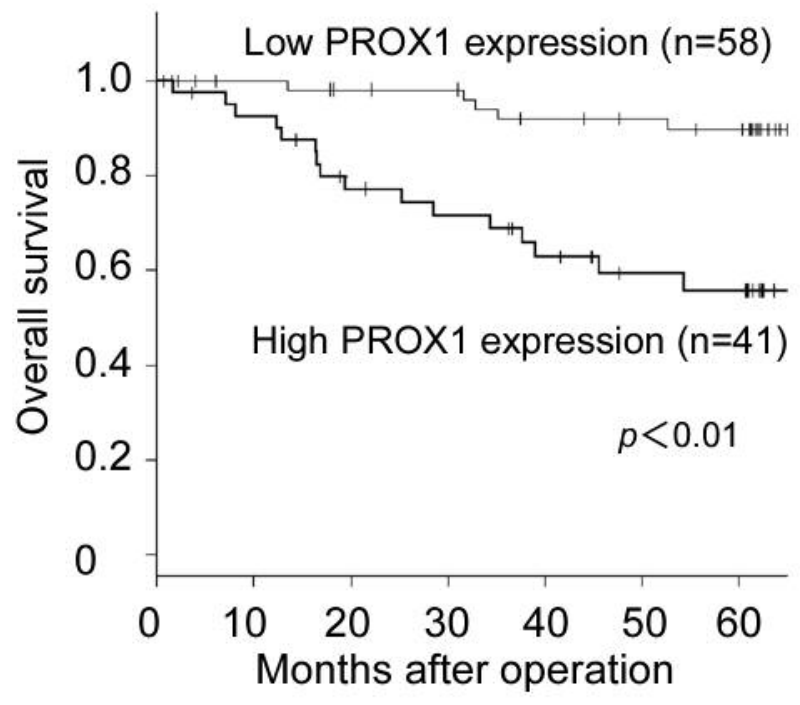

B

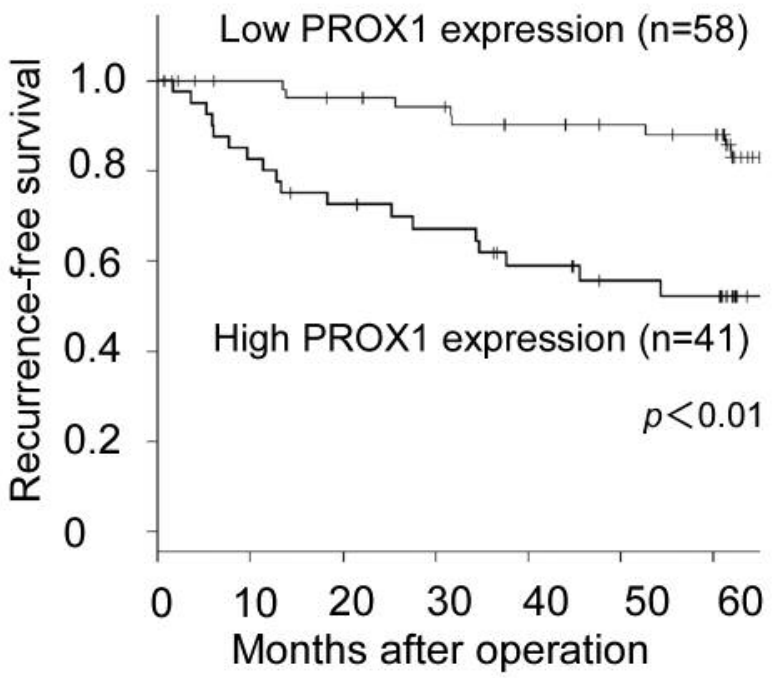

Figure 3. Prospero homeobox protein-1 (PROX1) expression levels are negatively correlated with prognostic significance. Kaplan-Meier curve for overall (A) and recurrence-free (B) survival of high and low PROX1 expression groups. Patients with high PROX1 expression had a poorer prognosis. p-Values were determined by the log-rank test at 60 months after surgery for gastric cancer.

a high PROX1 expression level in gastric cancer tissues was correlated with poor prognosis of patients with gastric cancer. In clinicopathological factors, PROX1 expression levels were well correlated with cancer stage, $\mathrm{N}$ factor, lymphatic vascular invasion, and vascular invasion in patients with gastric cancer. 
Oncogenic cellular behavior of gastric cancer cells was enhanced by PROX1 expression. This is consistent with previous studies suggesting that PROX1 is a tumor promoter in gastrointestinal cancer cells. PROXI knockdown reduced invasion, migration, and proliferation of colorectal cancer cells and esophageal cancer cells $(2,3)$. On the other hand, PROX1 knockdown was found to enhance proliferation of hepatic cancer cells and neuroblastoma $(4,6)$. Taken together, PROX1 is up-regulated in several human cancer types, and can be either a tumor promoter or suppressor. Currently it is unclear the reason why PROXI knockdown has differential impact on oncogenic cellular behavior depending on cancer type. Our in vitro results indicated that in gastric cancer cells, high PROX1 expression promoted oncogenic cellular behavior.

Our clinical study showed PROX1 expression levels to be correlated with prognosis in patients with gastric cancer. A positive correlation between PROX1 expression and tumor grade was reported in gastric cancer (10). It is likely that the measurement of PROX1 expression is useful for diagnosis of malignancy during pathological examination. Recent studies also suggested that prognosis in patients with high PROX1 expression was reduced in patients with colon cancer, esophageal cancer, and malignant astrocytic glioma $(2,3,11)$. However, these studies did not detect any difference in lymphatic invasion and vascular invasion between low and high PROX1 expression groups. Interestingly, our results for lymphatic invasion, vascular invasion and lymph node metastasis suggest that gastric cancer cells with high PROX1 expression easily invade the surrounding vasculature. In addition, the low recurrence-free survival rate we found for the high-PROX1 expression group suggests that PROX1 is involved not only in lymph node metastasis but also in hematogenous metastasis. A recent study demonstrated that cancer cells entering lymphatic vessels can invade lymph node blood vessels, enter the blood circulation, and colonize other distant organs $(12,13)$. It is, thus, possible that high PROX1 expression in gastric cancer causes lymphatic vascular invasion and lymph metastasis, leading to enhanced vascular invasion and hematogenous metastasis.

It has not been addressed how PROX1 expression in gastric cancer cells results in poor prognosis, as well as lymphatic vascular invasion and lymph node metastasis. It is intriguing that higher PROX1 expression in gastric cancer enhances the affinity to the lymphatic vessels in which PROX1 plays a crucial role. It has been reported that transcription factors that regulate PROX1 expression in lymphatic endothelial cells include sex determining region Y-box 18, nuclear factor-kappa B, homeobox D8, and chicken ovalbumin upstream promoter transcription factor II (13-16). Some of these and their related factors might be involved in PROX1 expression in gastric cancer. Other studies indicate that PROX1 regulates some inducers of epithelial-mesenchymal transition, including hypoxiainducible factor-1, forkhead box protein $\mathrm{C} 2$, integrin $\alpha 9$, and wingless-type mouse mammary tumor virus integration site family $/ \beta$-catenin, which enhance cell migration and invasion $(16,18-22)$. It will be important in future study to elucidate which pathways are activated to play a role in PROX1related oncogenic cellular behavior. This would clarify molecular mechanisms underlying the high PROX1 expression in gastric cancer cells which specifically increases lymphatic vascular invasion and lymph node metastasis.

In conclusion, PROX1 expression is significantly associated with prognosis in patients with gastric cancer. It may be possible to control cancer progression by suppressing PROX1 or its downstream partners in gastric cancer. PROX1 may be a promising prognostic biomarker and a new candidate for targeted therapy in gastric cancer.

\section{Acknowledgements}

The Authors thank Ms. Imagawa for technical assistance. This study was supported in part by JSPS KAKENHI Grant Numbers JP16K199300 (K.U.).

\section{References}

1 Escobedo $\mathrm{N}$ and Oliver G: Lymphangiogenesis: Origin, specification and cell fate determination. Annu Rev Cell Dev Biol 32: 677-691, 2016.

$2 \mathrm{Lu}$ MH, Huang CC, Pan MR, Chen HH and Hung WC: Prospero homeobox 1 promotes epithelial-mesenchymal transition in colon cancer cells by inhibiting E-cadherin via miR-9. Clin Cancer Res 18: 6416-6425, 2012.

3 Yokobori T, Bao P, Fukuchi M, Altan B, Ozawa D, Rokudai S, Bai T, Kumakura Y, Honjo H, Hara K, Sakai M, Sohda M, Miyazaki T, Ide M, Nishiyama M, Oyama T and Kuwano H: Nuclear PROX1 is associated with hypoxia-inducible factor 1alpha expression and cancer progression in esophageal squamous cell carcinoma. Ann Surg OncoI 22 (Suppl 3): S15661573,2015

4 Foskolou IP, Stellas D, Rozani I, Lavigne MD and Politis PK: PROX1 suppresses the proliferation of neuroblastoma cells via a dual action in p27-KIP1 and CDC25A. Oncogene 32: 947-960, 2013.

5 Versmold B, Felsberg J, Mikeska T, Ehrentraut D, Kohler J, Hampl JA, Rohn G, Niederacher D, Betz B, Hellmich M, Pietsch T, Schmutzler RK and Waha A: Epigenetic silencing of the candidate tumor suppressor gene PROX1 in sporadic breast cancer. Int J Cancer 121: 547-554, 2007.

6 Shimoda M, Takahashi M, Yoshimoto T, Kono T, Ikai I and Kubo H: A homeobox protein, PROX1, is involved in the differentiation, proliferation and prognosis in hepatocellular carcinoma. Clin Cancer Res 12: 6005-6011, 2006.

7 Harlow E and Lane D: Mounting samples in gelvatol or mowiol. CSH Protoc. 2006 Cold Spring Harbor Laboratory Press, NY.

8 Sobin LH GM, Wittekind C. International Union Against Cancer (UICC) TNM Classification of Malignant Tumours, Seventh Edition. New York: Wiley-Liss; 2010. 
9 Kanda Y: Investigation of the freely available easy-to-use software 'EZR' for medical statistics. Bone Marrow Transplant 48: 452-458, 2013.

10 Taban, O, Cimpean, A. M, Raica, M and Olariu, S: PROX1 expression in gastric cancer: from hypothesis to evidence. Anticancer Res 34: 3439-3446, 2014.

11 Elsir T, Eriksson A, Orrego A, Lindstrom MS and Nister M: Expression of PROX1 is a common feature of high-grade malignant astrocytic gliomas. J Neuropathol Exp Neurol 69: 129-138, 2010.

12 Brown M, Assen FP and Leithner A: Lymph node blood vessels provide exit routes for metastatic tumor cell dissemination in mice. Science 359: 1408-1411, 2018.

13 Pereira ER and Kedrin D: Lymph node metastases can invade local blood vessels, exit the node and colonize distant organs in mice. Science 359: 1403-1407, 2018.

14 Francois M, Caprini A, Hosking B, Orsenigo F, Wilhelm D, Browne C, Paavonen K, Karnezis T, Shayan R, Downes M, Davidson T, Tutt D, Cheah KS, Stacker SA, Muscat GE, Achen MG, Dejana E and Koopman P: SOX18 induces development of the lymphatic vasculature in mice. Nature 456: 643-647, 2008.

15 Flister MJ, Volk LD and Ran S: Characterization of PROX1 and VEGFR-3 expression and lymphatic phenotype in normal organs of mice lacking p50 subunit of NF-kappaB. Microcirculation 18: 85-101, 2011.

16 Harada K, Yamazaki T, Iwata C, Yoshimatsu Y, Sase H, Mishima K, Morishita Y, Hirashima M, Oike Y, Suda T, Miura N, Watabe $\mathrm{T}$ and Miyazono K: Identification of targets of PROX1 during in vitro vascular differentiation from embryonic stem cells: functional roles of HOXD8 in lymphangiogenesis. J Cell Sci 122: 3923-3930, 2009.

17 Srinivasan RS, Geng X, Yang Y, Wang Y, Mukatira S, Studer M, Porto MP, Lagutin O and Oliver G: The nuclear hormone receptor Coup-TFII is required for the initiation and early maintenance of PROX1 expression in lymphatic endothelial cells. Genes Dev 24: 696-707, 2010.
18 Liu Y, Zhang JB, Qin Y, Wang W, Wei L, Teng Y, Guo L, Zhang B, Lin Z, Liu J, Ren ZG, Ye QH and Xie Y: PROX1 promotes hepatocellular carcinoma metastasis by way of up-regulating hypoxia-inducible factor 1alpha expression and protein stability. Hepatology 58: 692-705, 2013.

19 Mishima K, Watabe T, Saito A, Yoshimatsu Y, Imaizumi N, Masui S, Hirashima M, Morisada T, Oike Y, Araie M, Niwa H, Kubo H, Suda T and Miyazono K: PROX1 induces lymphatic endothelial differentiation via integrin alpha9 and other signaling cascades. Mol Biol Cell 18: 1421-1429, 2007.

20 Liu Y, Ye X, Zhang JB, Ouyang H, Shen Z, Wu Y, Wang W, Wu J, Tao S, Yang X, Qiao K, Zhang J, Liu J and Fu Q: PROX1 promotes hepatocellular carcinoma proliferation and sorafenib resistance by enhancing beta-catenin expression and nuclear translocation. Oncogene 34: 5524-5535, 2015.

21 Petrova TV, Nykanen A, Norrmen C, Ivanov KI andersson LC, Haglund C, Puolakkainen P, Wempe F, von Melchner H, Gradwohl G, Vanharanta S, Aaltonen LA, Saharinen J, Gentile M, Clarke A, Taipale J, Oliver G and Alitalo K: Transcription factor PROX1 induces colon cancer progression by promoting the transition from benign to highly dysplastic phenotype. Cancer Cell 13: 407-419, 2008.

22 Ragusa S, Cheng J, Ivanov KI, Zangger N, Ceteci F, BernierLatmani J, Milatos S, Joseph JM, Tercier S, Bouzourene H, Bosman FT, Letovanec I, Marra G, Gonzalez M, Cammareri P, Sansom OJ, Delorenzi M and Petrova TV: PROX1 promotes metabolic adaptation and fuels outgrowth of WNT(high) metastatic colon cancer cells. Cell Rep 8: 1957-1973, 2014.

Received September 18, 2018

Revised September 29, 2018 Accepted October 8, 2018 